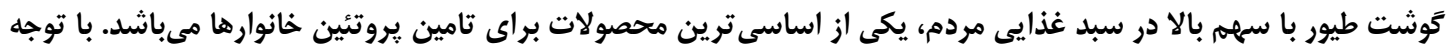

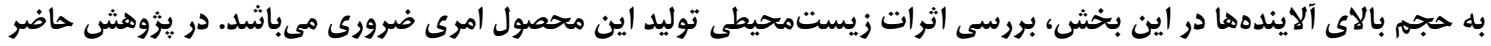

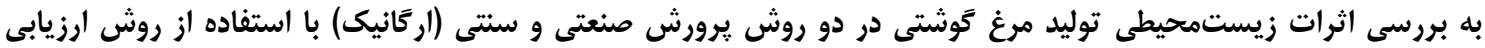

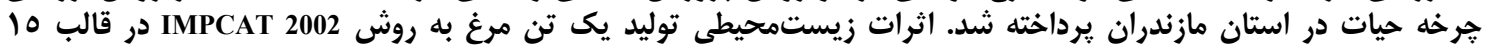

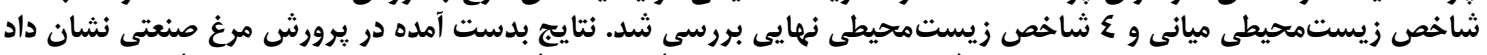

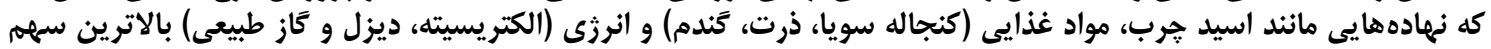

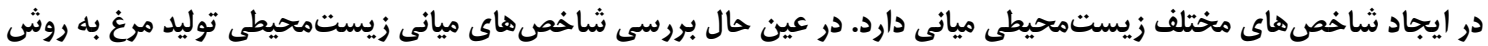

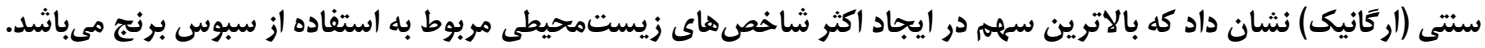

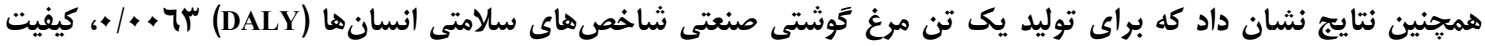

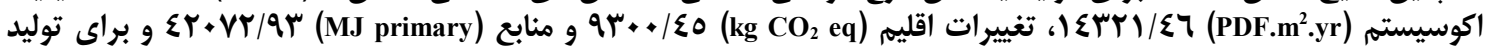

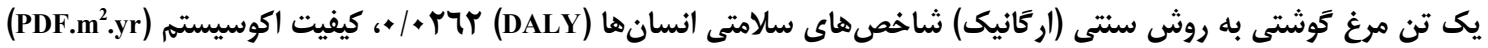

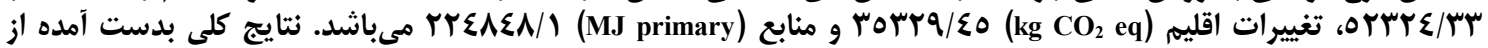

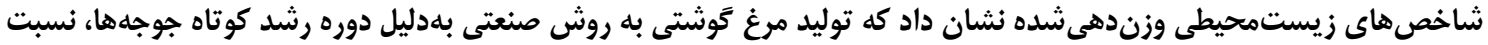

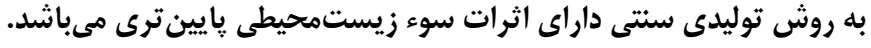

وازههاى كليدى: اثرات زيستمحيطى، مرغ تَوشتى، IMPACT 2002 ارزيابى جرخه حيات

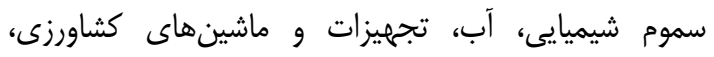

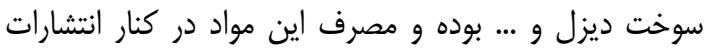

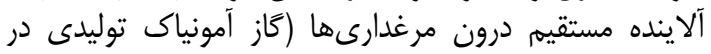

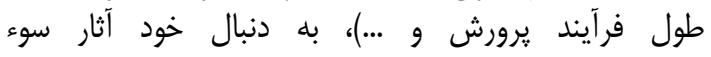

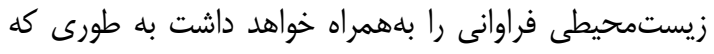

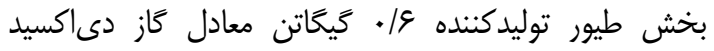

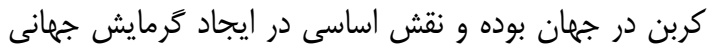

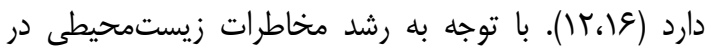

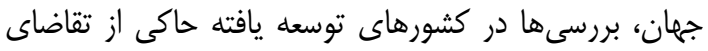

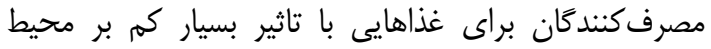

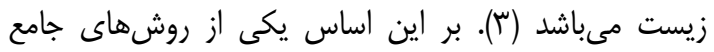

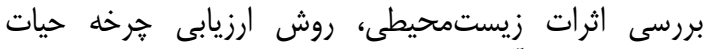

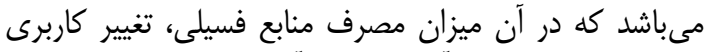

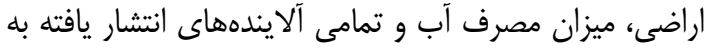

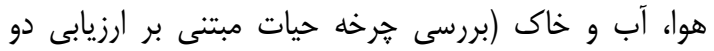

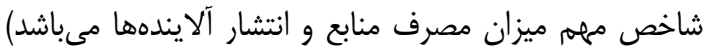

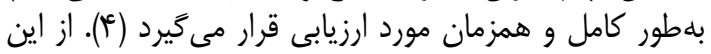

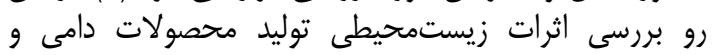

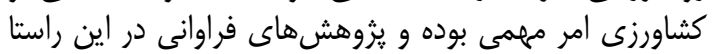
انجام شده است.

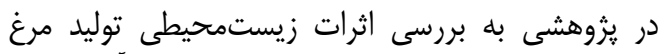

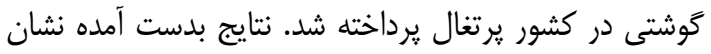

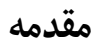
با افزايش روزافزون جمعيت و تغيير در استانداردهاى

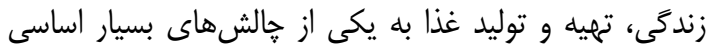

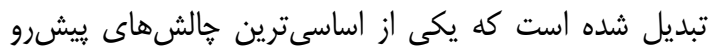

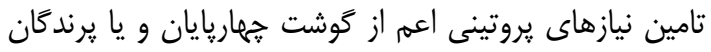

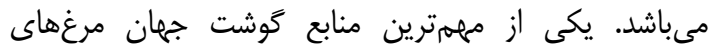

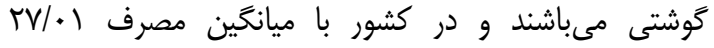

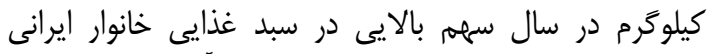

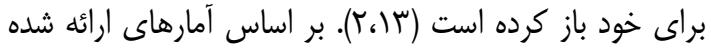

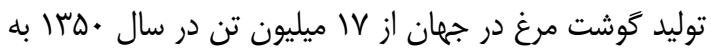

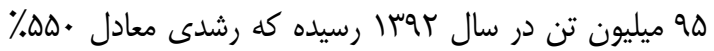

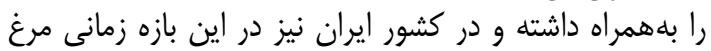

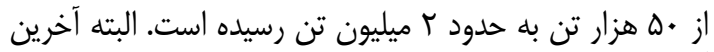

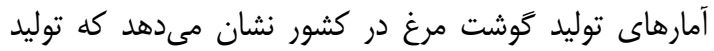

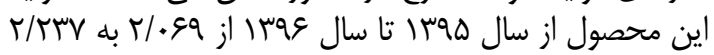

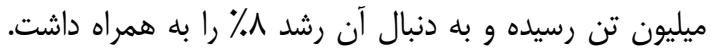

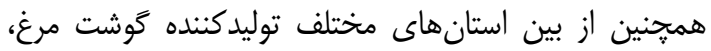

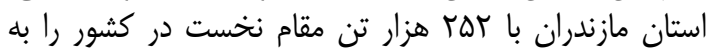

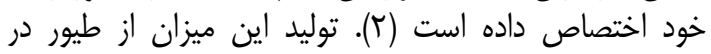

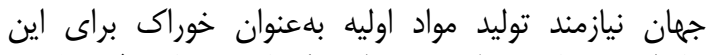

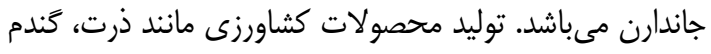

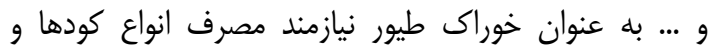


شاخصهاى سوء زيستمحيطى مربوط به فرآيند توليد غذا

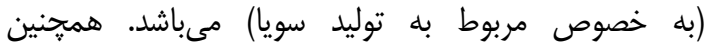

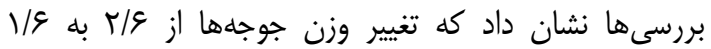

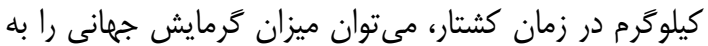

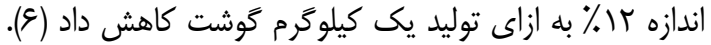

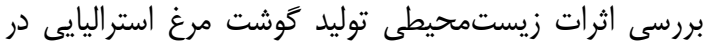

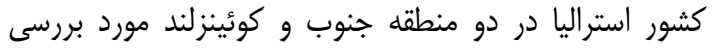

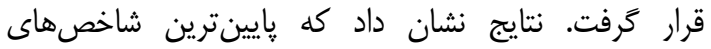

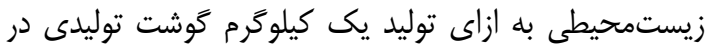

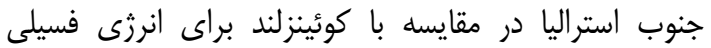

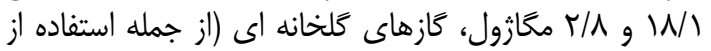

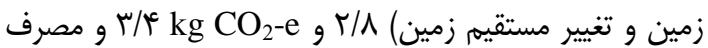

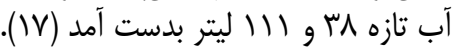

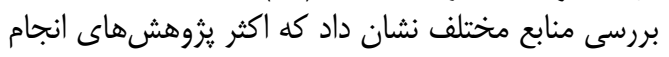

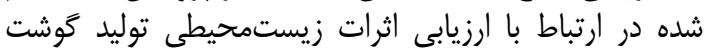

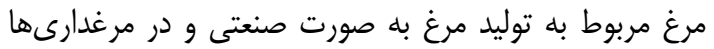

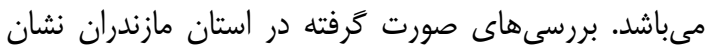

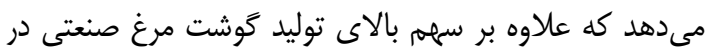

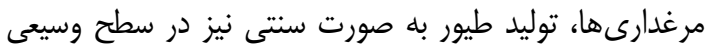

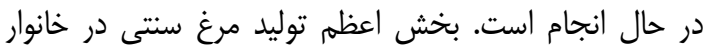

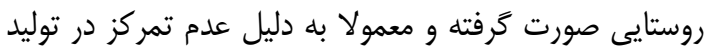

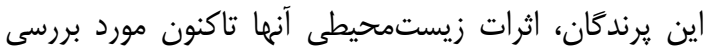

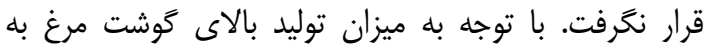

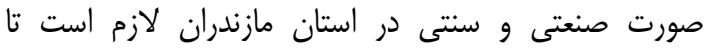

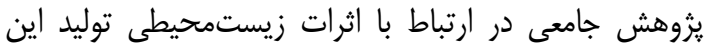

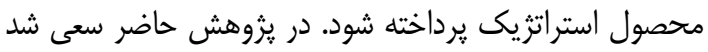

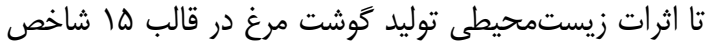

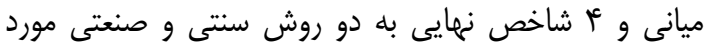

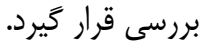

\section{مواد و روشها}

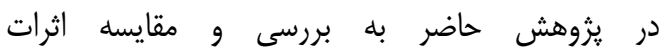
زيستمحيطى توليد مرغ كوشتى در قالب دو سناريوى مختلف رونف

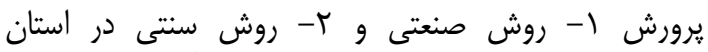

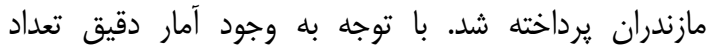

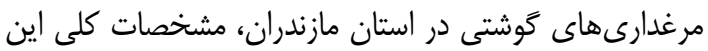

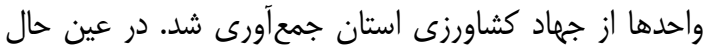

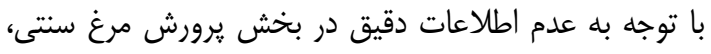

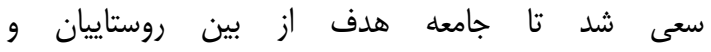

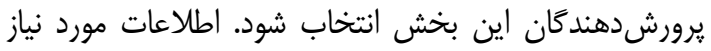

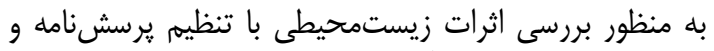

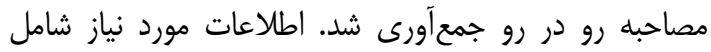

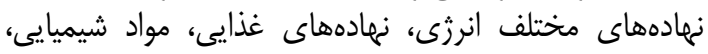
نيروى انسانى و ماشينى بودان

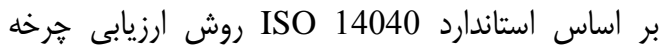

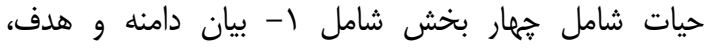

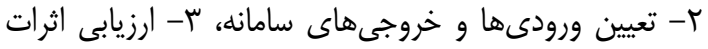
زيستمحيطى و أ- تفسير نتايج مى باشد (^).
داد كه مزرعه توليد مرغ گتوشتى عامل اصلى اثرات

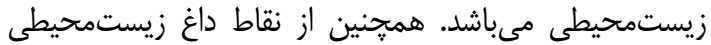

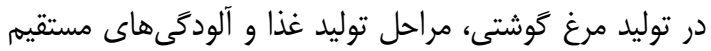

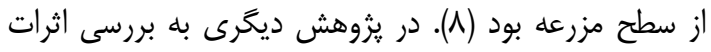

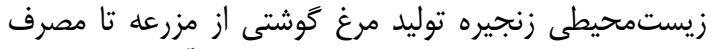

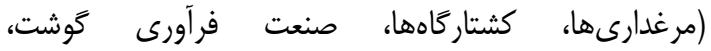

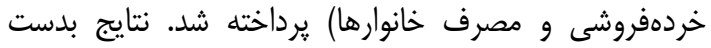

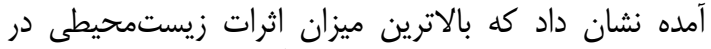

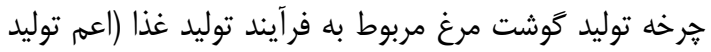

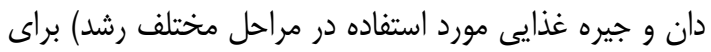

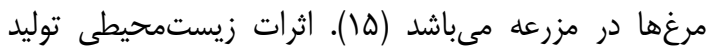

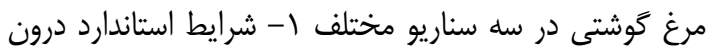

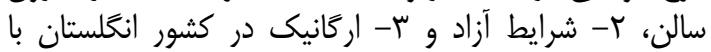

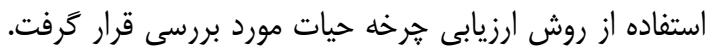

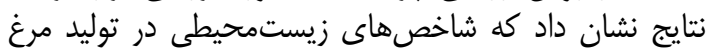

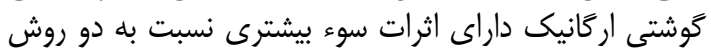

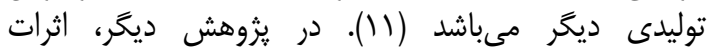

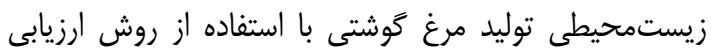

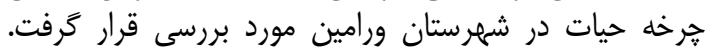
نتايج بدست آمده نشان داد كه ميزان شاخصني

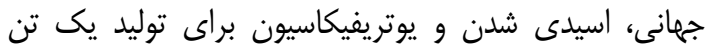

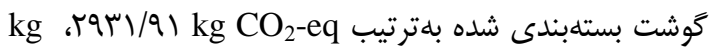
و أFD

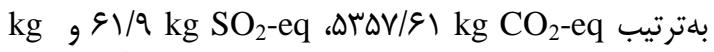
19/ 19 براى فصل زمستان بدست آمد (•) $\mathrm{PO}_{4}$-eq

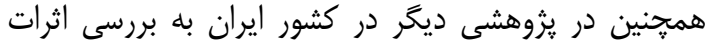

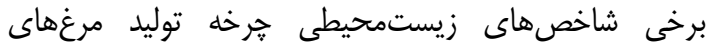

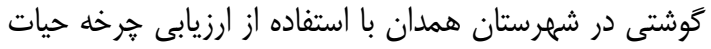

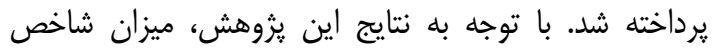

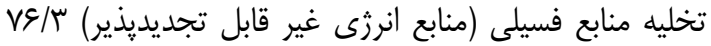

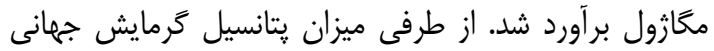

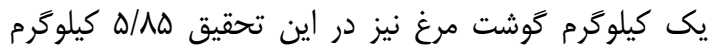

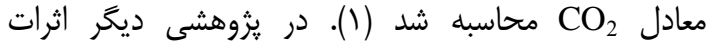

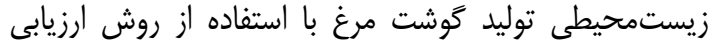

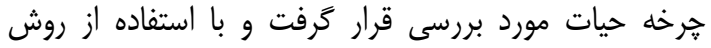

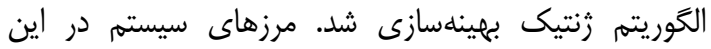

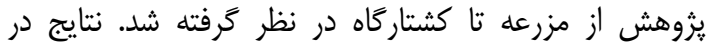

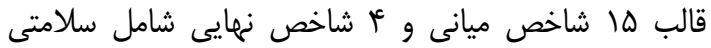

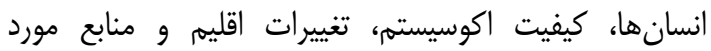

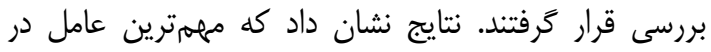

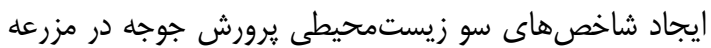

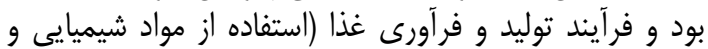

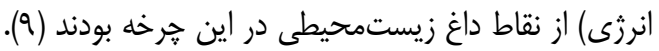

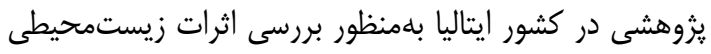

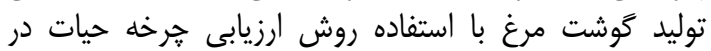

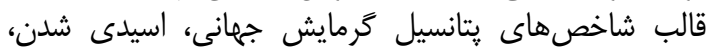

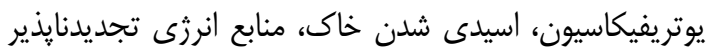

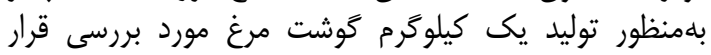

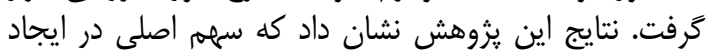




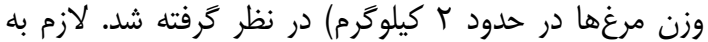

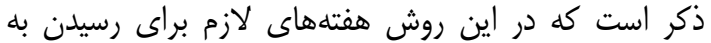

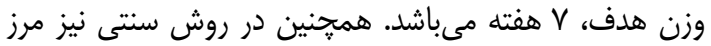

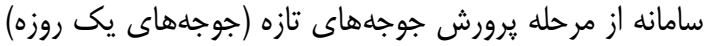

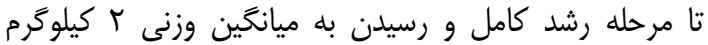

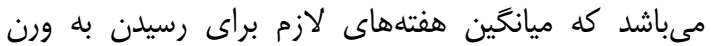

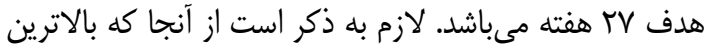

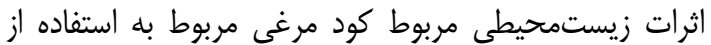

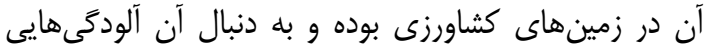
مانند

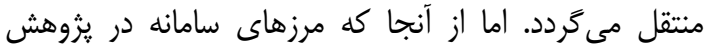

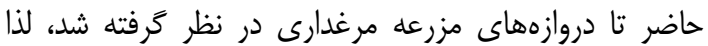
اثرات زيستمحيطى كود مرغى در نظر كرفته نشاري.
تعيين دامنه و هدف

هدف از انجام اين يزوهش بروف بروسى اثرات زيستمحيطى

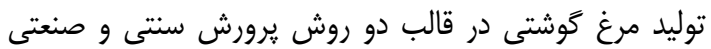

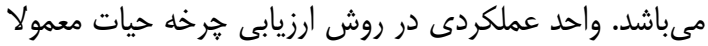

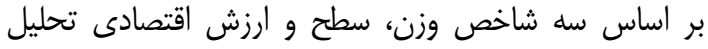

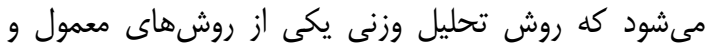

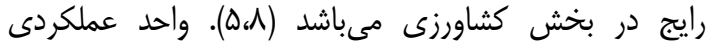

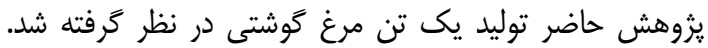

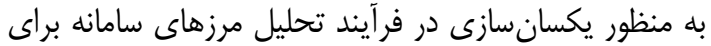

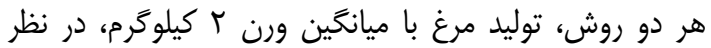

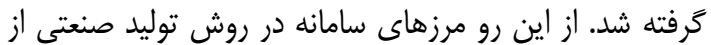

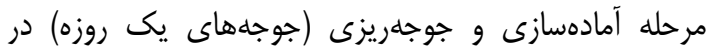
مرغدارى تا مرحله يرورش كامل مرغ و تخليه سالن (ميانكين

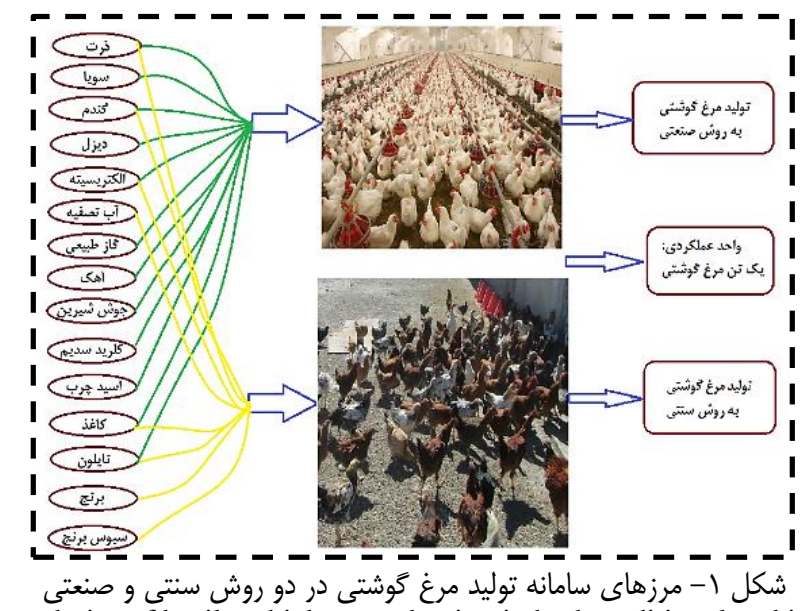

Figure 1. The boundaries of broiler chicken production in both traditional and industrial methods

صنعتى شامل جيره غذايى (كنجاله سويا، ذرت، گَندم و ...)،

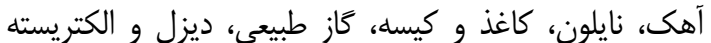

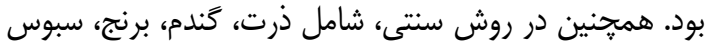

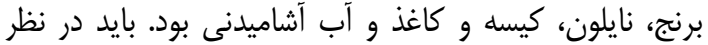

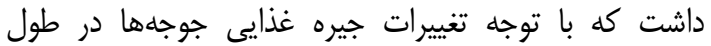

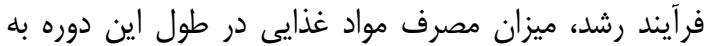

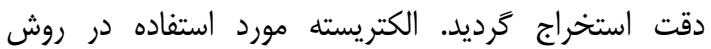

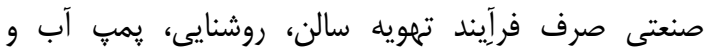

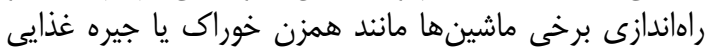

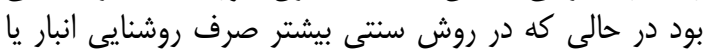

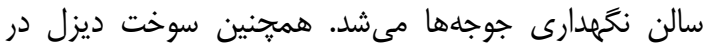

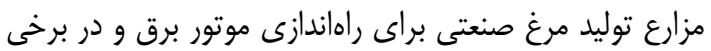

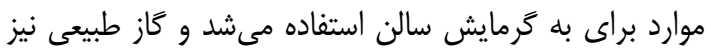

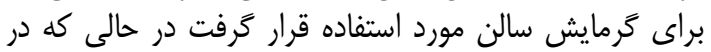

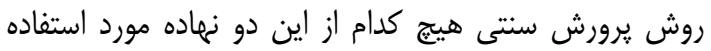

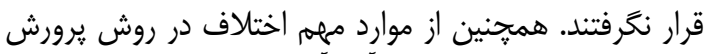

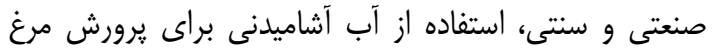

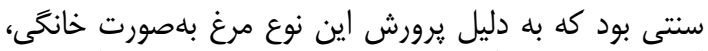

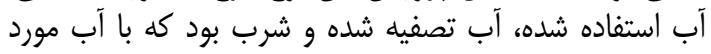

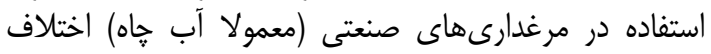

مزرعه يرورش مرغ

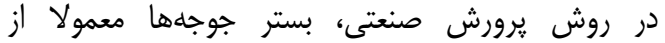

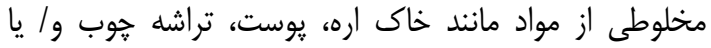

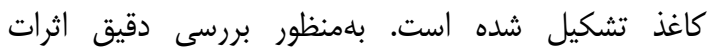

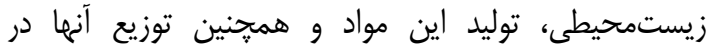

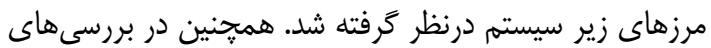

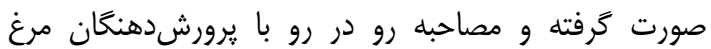

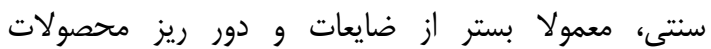

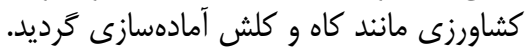

آنتىبيوتيكهاورئ وانذ كاهو واكسنها

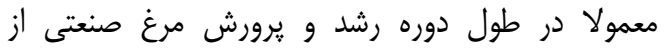

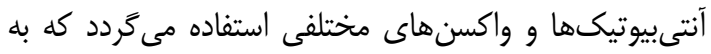

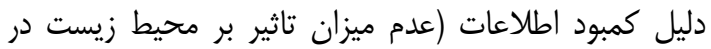

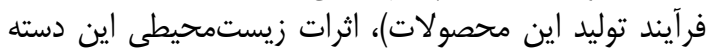

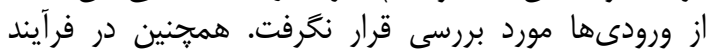

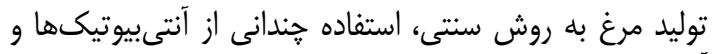

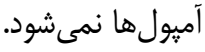

ورودىها و خروجى إنهاى سامانه

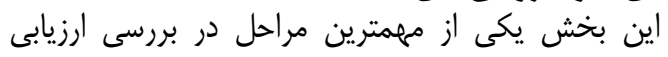

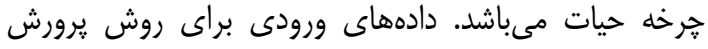


تاثيركذارى هر يك از نهادههاى ورودى در ايجاد اين شاخصها مشخص خواهد شد.

\section{نتايج و بحث}

بررسى شاخصهاى زيستمحيطى (شاخصهاى ميانى)

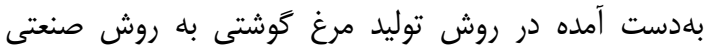

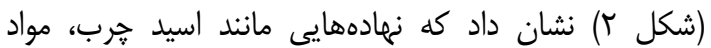

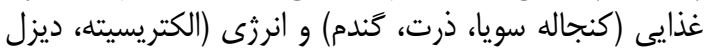

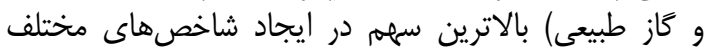

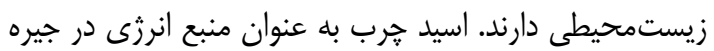

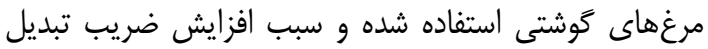

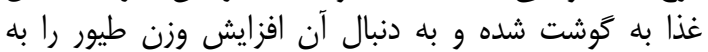

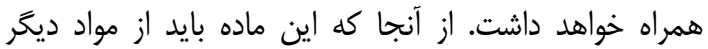

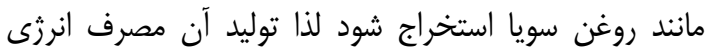

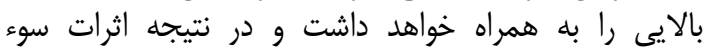

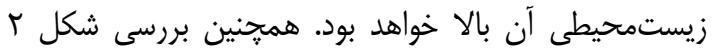

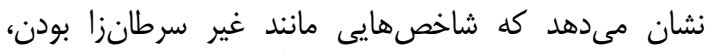
سميت خاك و سميت محيطهاى آبى داراى مانى مقادير منفى مانى

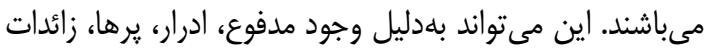

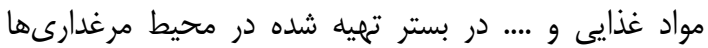

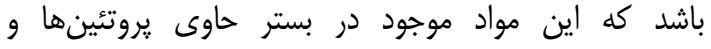

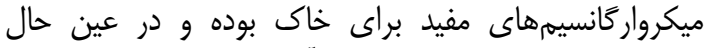

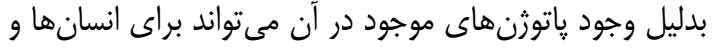

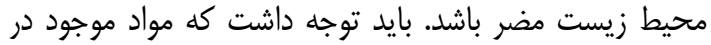

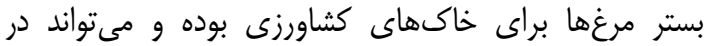

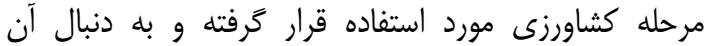

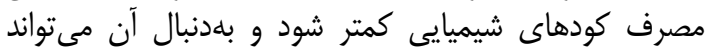

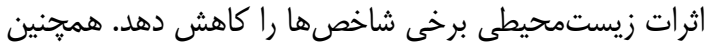

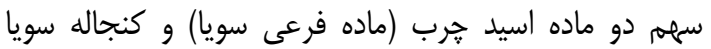

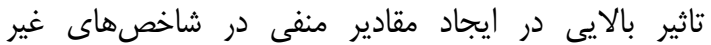

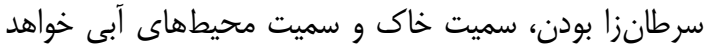

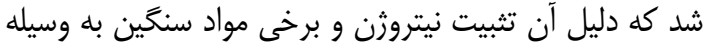

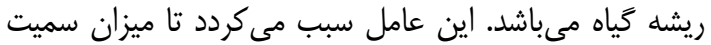

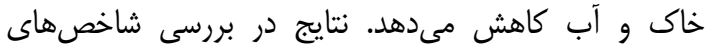

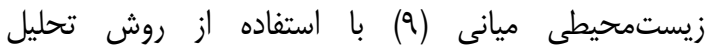

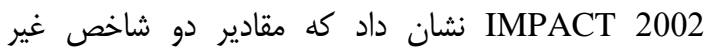
سرطانزا بودن و سميت خاك منفى بدست آمدند كاد كه با بانتايج ئزوهش حاضر مطابقت دارد.

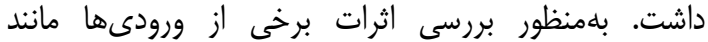

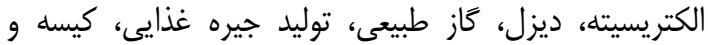

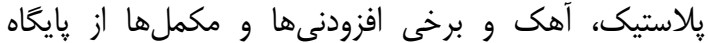

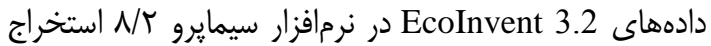
شد (V). در بخش خروجى آلايندههاى مستقيم (انتشارات

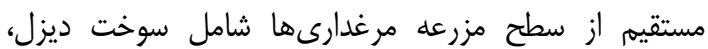

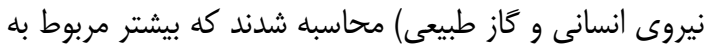

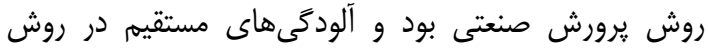

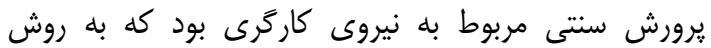

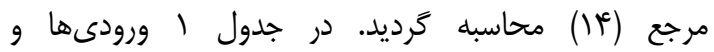

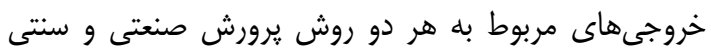

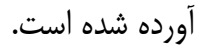

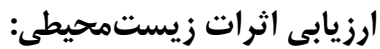

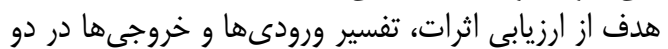

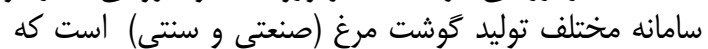

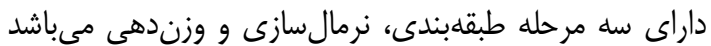

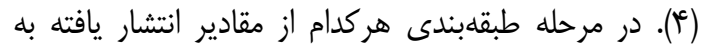

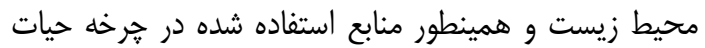
محصول، به اثر زيست محيطى مربوطه نسبت دمان داده مى شود. در

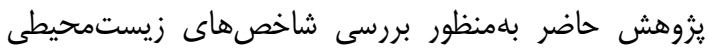
ميانى و نهايى از روش تحليل

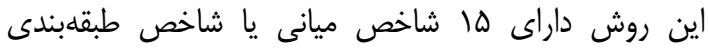

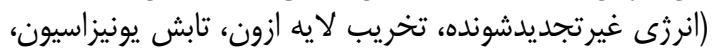

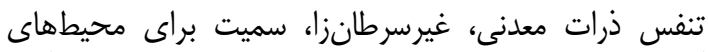

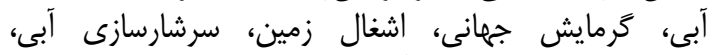

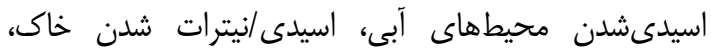

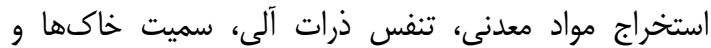

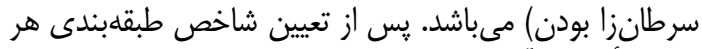

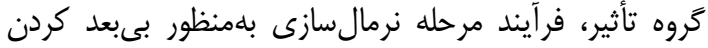

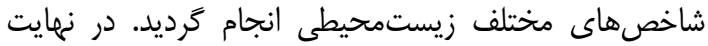
فاكتور وزندهى در قالب ع أ شاخص نهايى (سلامتى انسانها،

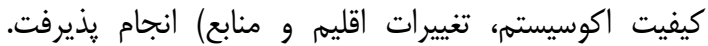

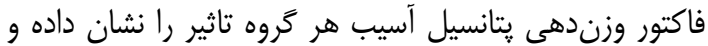

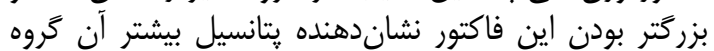
براى لطمه به محيط زيست مى باشند. تفسير نتايج

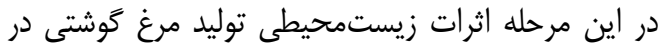

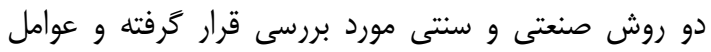
تاثير كذار در ايجاد شاخصهاى سوء زيستمحيطى و ميزان 
Table 1. Inputs and outputs of one ton of bـ جدول - ورودىها و خروجى هاى توليد يك تن مرغ كوشتى به دو روش صنعتى و ستي

\begin{tabular}{|c|c|c|c|c|c|}
\hline \multicolumn{6}{|c|}{ روش توليد صنعتى } \\
\hline \multicolumn{3}{|c|}{ ورودىها } & \multicolumn{3}{|c|}{ خروجىها (انتشار به هوا) } \\
\hline ورودىها & واحد & ميزان توليد & خروجىها & واحد & ميزان توليد \\
\hline ديزل & $\mathrm{L}$ & TQ/Tr & $\mathrm{N}_{2} \mathrm{O}$ & $\mathrm{kg}$ &.$/ .+4$ \\
\hline آهى & $\mathrm{kg}$ & ( & $\mathrm{C}_{6} \mathrm{H}_{6}$ & $\mathrm{~kg}$ & . . r r \\
\hline جوش شيرين & $\mathrm{kg}$ & $r / 4)$ & P.M. $<2.5$ um & $\mathrm{kg}$ &.$/ N Q T$ \\
\hline كلريد سديم & $\mathrm{kg}$ & $.1 . .99$ & $\mathrm{HgO}$ & $\mathrm{kg}$ & $r /\{\Delta \times)^{-1 .}$ \\
\hline كربنات كلسيه & $\mathrm{kg}$ & $\Delta q / v$. & $\mathrm{NO}_{\mathrm{x}}$ & $\mathrm{kg}$ & $1 / 01$ \\
\hline اسيد هرب & $\mathrm{kg}$ & $F \Delta V / 11$ & $\mathrm{CO}_{2}$ (fossil) & $\mathrm{kg}$ & $1.8 / \mu 1$ \\
\hline كنجاله سويا & $\mathrm{kg}$ & $|\&| / 94$ & $\mathrm{CH}_{4}$ & $\mathrm{~kg}$ & $.1 . .+4 \varphi^{2}$ \\
\hline كندم & $\mathrm{kg}$ & IE/MET & $\mathrm{C}_{20} \mathrm{H}_{12}$ & $\mathrm{~kg}$ & $N /|V \times|{ }^{-11}$ \\
\hline ذرت & $\mathrm{kg}$ & $1 \cdot r V / V I$ & $\mathrm{CO}$ & $\mathrm{kg}$ & rוr/. \\
\hline كاغذ و كيسه & $\mathrm{kg}$ & $.1 . .91$ & $\mathrm{Cd}$ & $\mathrm{kg}$ & $r / \mathcal{F}|x| .^{-v}$ \\
\hline 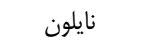 & $\mathrm{kg}$ & . I. TID & NMVOC & $\mathrm{kg}$ & $.1 .9 V$ \\
\hline الكتريسيته & $\mathrm{kWh}$ & rA./Fr & $\mathrm{Se}$ & $\mathrm{kg}$ & $r / \mathcal{E} r \times 1 .^{-\gamma}$ \\
\hline كاز طبيعى & $\mathrm{m}^{3}$ & IDN/gr & $\mathrm{SO}_{\mathrm{x}}$ & $\mathrm{kg}$ & $r / 49 \times 1 .{ }^{-9}$ \\
\hline \multirow[t]{16}{*}{ كاركر } & $\mathrm{h}$ & $9 \Lambda \cdot 10 \Lambda$ & $\mathrm{Zn}$ & $\mathrm{kg}$ & $r / 4 \cdot \times 1 \cdot{ }^{-\phi}$ \\
\hline & & & $\mathrm{Ni}$ & $\mathrm{kg}$ & $r / r V \times 1 .^{-9}$ \\
\hline & & & $\mathrm{Cr}$ & $\mathrm{kg}$ & $1 / 99 \times 1 . .^{-9}$ \\
\hline & & & $\mathrm{Cu}$ & $\mathrm{kg}$ & $\Delta / V \nabla \times 1 \cdot{ }^{-\Delta}$ \\
\hline & & & $\mathrm{C}_{3} \mathrm{H}_{8}$ & $\mathrm{~kg}$ & $|/ 9| x \mid \cdot^{-9}$ \\
\hline & & & $\mathrm{C}_{2} \mathrm{H}_{4} \mathrm{O}$ & $\mathrm{kg}$ & $N /|V \times| \cdot \cdot^{-9}$ \\
\hline & & & $\mathrm{CH}_{2} \mathrm{O}$ & $\mathrm{kg}$ & $N /|V \times| .^{-V}$ \\
\hline & & & $\mathrm{C} 2 \mathrm{H} 4 \mathrm{O} 2$ & $\mathrm{~kg}$ & $|/ r| r \mid \cdot^{-9}$ \\
\hline & & & $\mathrm{CH}_{3} \mathrm{CH}_{2} \mathrm{COOH}$ & $\mathrm{kg}$ & $\left|/ q^{\prime} \times\right| \cdot \cdot^{-v}$ \\
\hline & & & $\mathrm{PAH}$ & $\mathrm{kg}$ & $\mid 1 / r \cdot \times 1)^{-\Delta}$ \\
\hline & & & $\mathrm{SO} 2$ & $\mathrm{~kg}$ & . \\
\hline & & & $\mathrm{C}_{4} \mathrm{H}_{10}$ & $\mathrm{~kg}$ & $\Delta / Y \Psi x \mid \cdot .^{-9}$ \\
\hline & & & $\mathrm{C} 7 \mathrm{H} 8$ & $\mathrm{~kg}$ & $\left|/ q^{\mu} \times\right| .^{-9}$ \\
\hline & & & $\mathrm{C}_{5} \mathrm{H}_{12}$ & $\mathrm{~kg}$ & $9 / \Delta T \times \mid .^{-9}$ \\
\hline & & & $\mathrm{CO}_{2}$ (Human) & $\mathrm{kg}$ & $\mid r V / F i$ \\
\hline & & & $\mathrm{NH}_{3}$ & $\mathrm{~kg}$ & $9 V(\Lambda \cdot x \mid)^{-\Delta}$ \\
\hline \multicolumn{6}{|c|}{ روش توليد سنتى } \\
\hline ذرت & $\mathrm{kg}$ & $M F \wedge D / F$. & $\mathrm{CO}_{2}$ & $\mathrm{~kg}$ & V9)/\%r \\
\hline كَندم & $\mathrm{kg}$ & $\mid r+1.1 .1$ & & & \\
\hline برنج & $\mathrm{kg}$ & $\| 11 \% / r$. & & & \\
\hline سبوس برنج & $\mathrm{kg}$ & १११५//Q & & & \\
\hline آب تصفيه شده & $\mathrm{m}^{3}$ & roqTS & & & \\
\hline كاغذ و كيسه & $\mathrm{kg}$ & $\mid r / 9$ & & & \\
\hline نايلون & $\mathrm{kg}$ & $r / v$. & & & \\
\hline كاركر & $\mathrm{h}$ & $11 r \cdot / 4$ & & & \\
\hline الكتر يسيته & $\mathrm{kWh}$ & $r \Delta \cdot / \Delta \Delta$ & & & \\
\hline
\end{tabular}




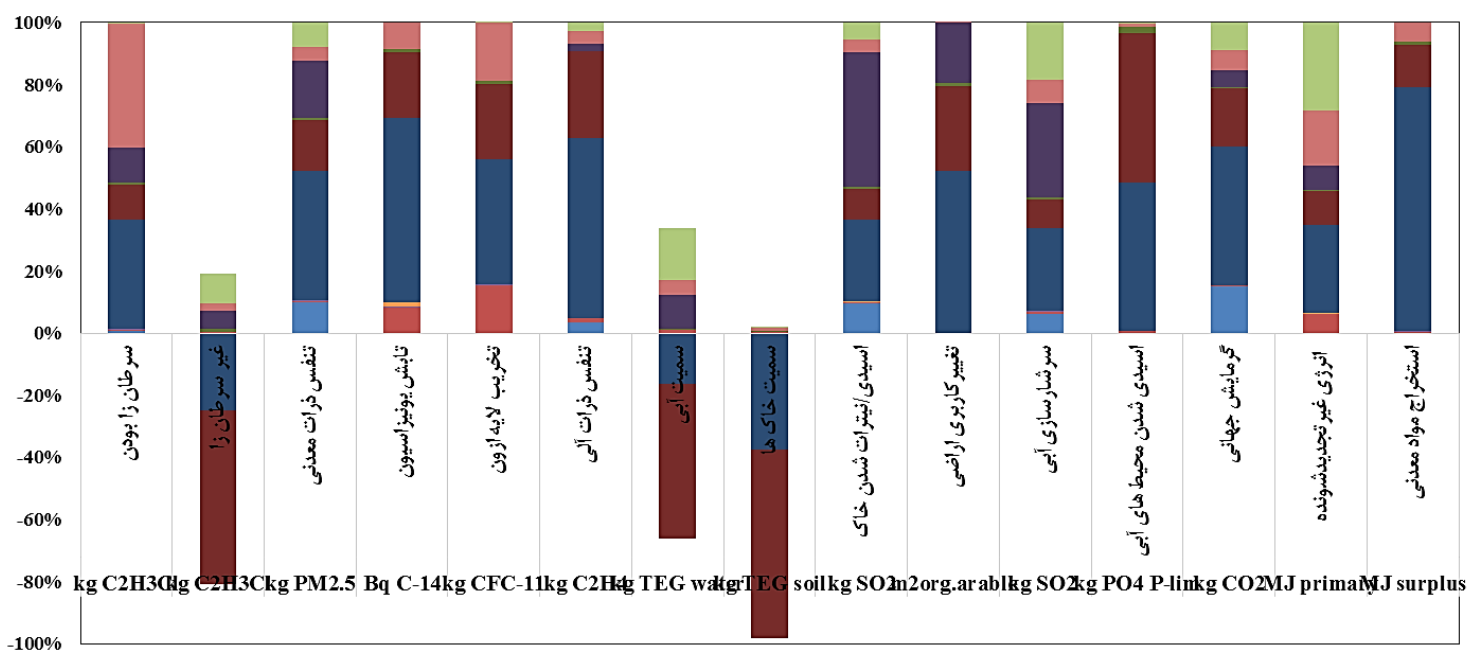

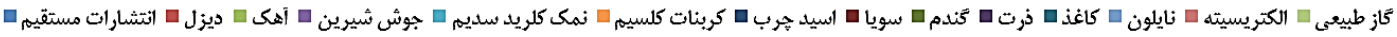

شكل r- سهم نهادههاى ورودى بر شاخصهاى ميانى زيستمحيطى توليد يكى تن مرغ گوشتى در روش توليد صنعتى

Figure 2. Contribution of inputs to midpoint environmental indicators of the broiler chicken production in the industrial method

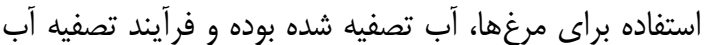

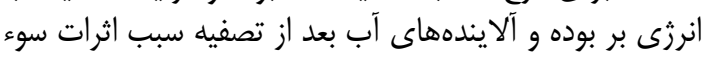

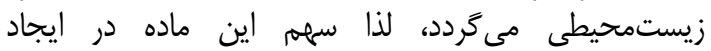

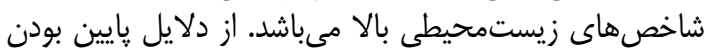

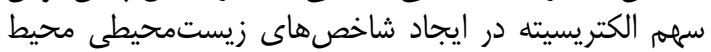

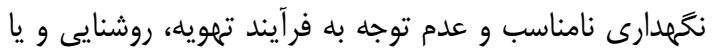

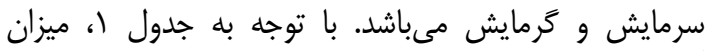

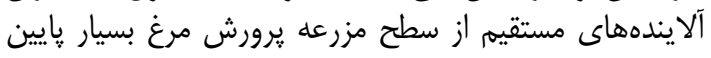

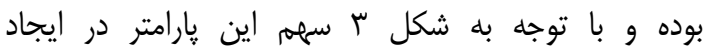

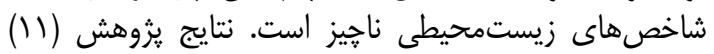

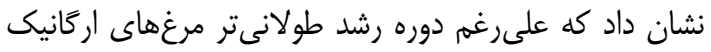

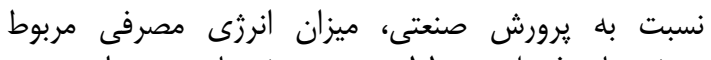

سوختهاى فسيلى در طول دوره برورش پإيين بوده است.
بررسى شاخصهاى ميانى زيستمحيطى توليد مرغ به

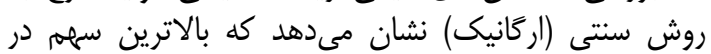

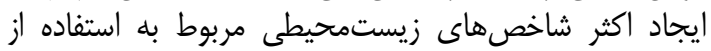

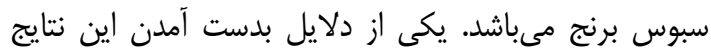

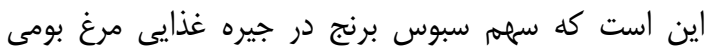
بهدليل ارزانى و فراوان بودن آن دران دران استان مازندران بهدرديل

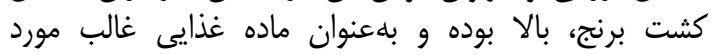

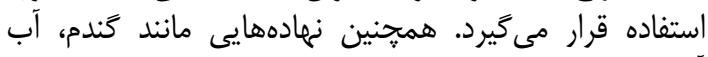

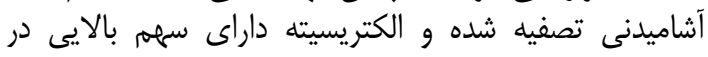

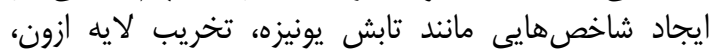

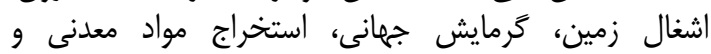

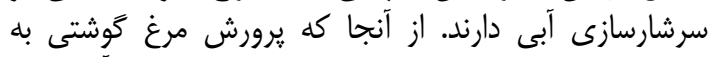
روش سنتى در خانهایى روستاييان انجام شده و آب مورد آنى

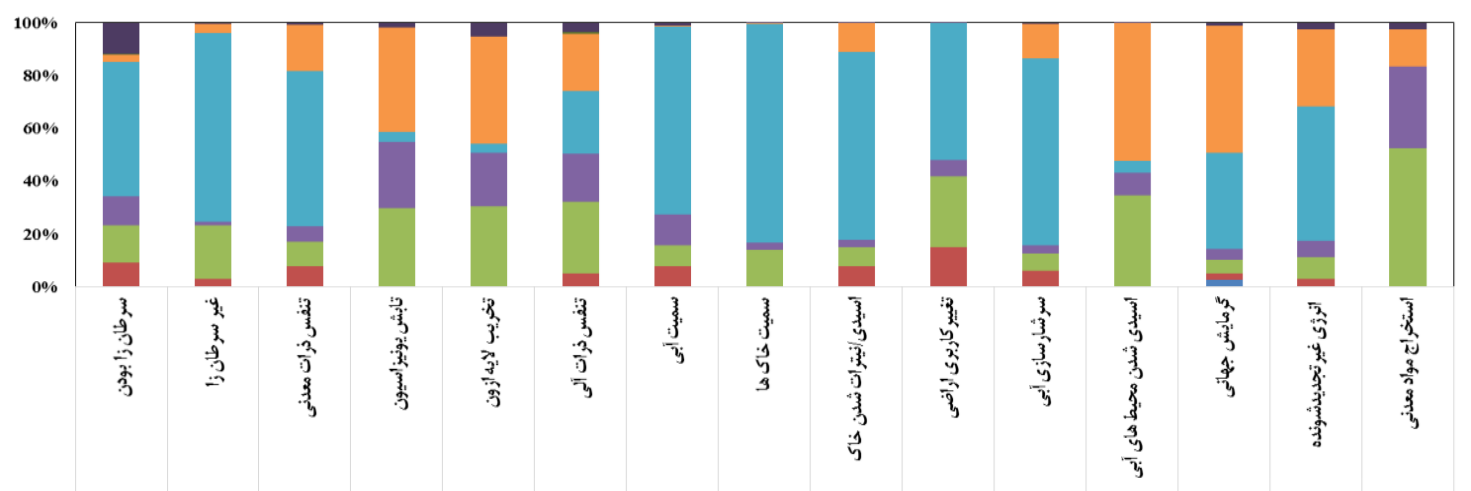

kg C2H3Ckg C2H3Clkg PM2.5 Bq C-14 kg CFC-11 kg C2Hug TEG wakg TEG soil kg SO2m2org.ar ablekg SO2kg PO4 P-limkg CO2 MJ primarMJ surplus

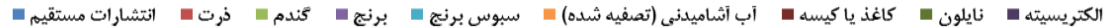

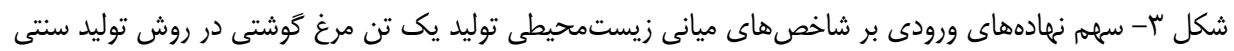

Figure 3. Contribution of inputs to midpoint environmental indicators of the broiler chicken production in the traditional method 
مزرعه) و غير مستقيم (آلايندههاى مربوط به توليد الكتريسيته

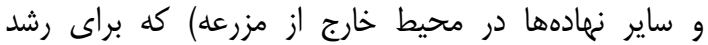

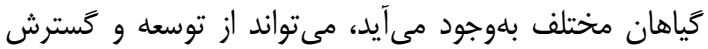

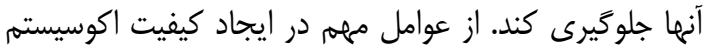

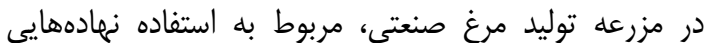

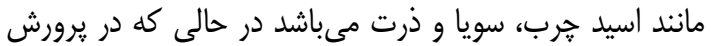

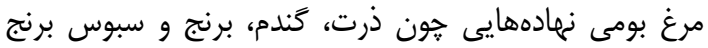

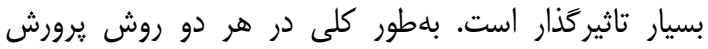

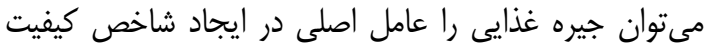

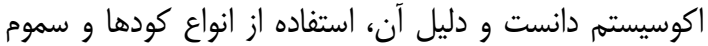
شيميايى در توليد محصولات مختلف كشاورزى مئى دياشد. وجود نيترات و فسفات براى حيات ضرورى بول بوده و اين عناصر

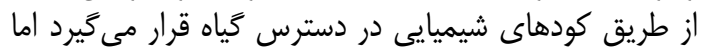

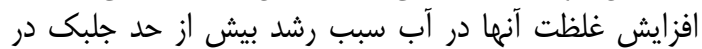

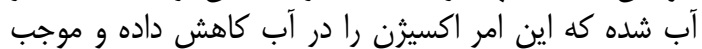
تخريب اكوسيستم مئشود.

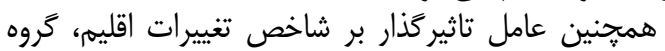

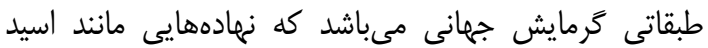

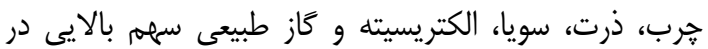
ايجاد اين شاخص دارند. فرآيند توليد الكتريسته و سوزاندن إندان

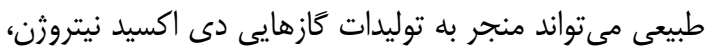

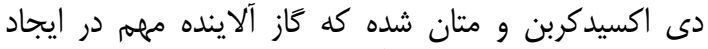

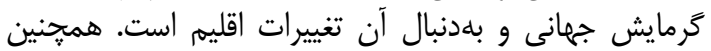

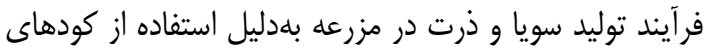

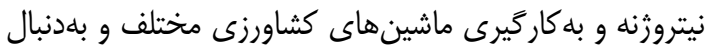

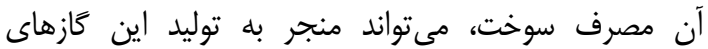

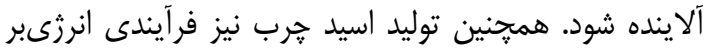

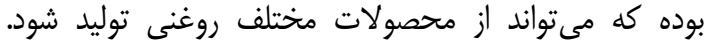

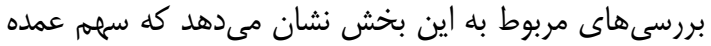

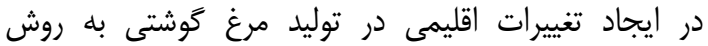

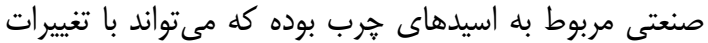

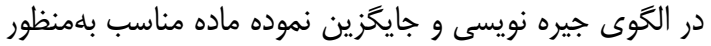

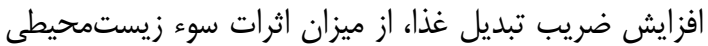

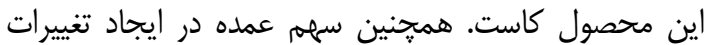

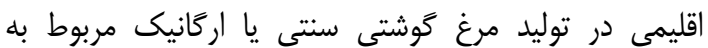

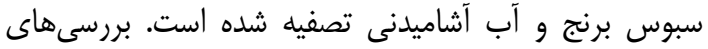

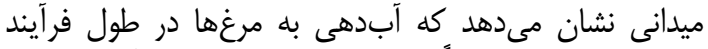

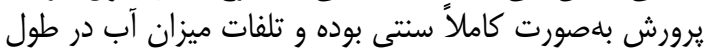

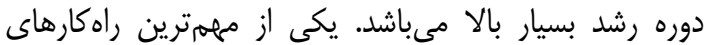

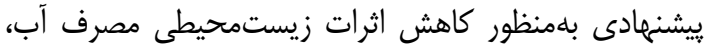

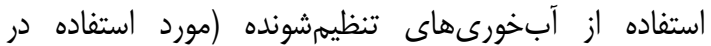

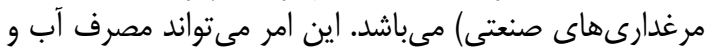

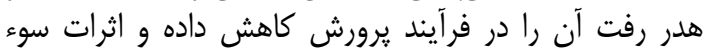

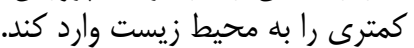

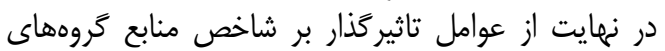

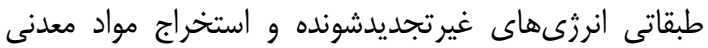

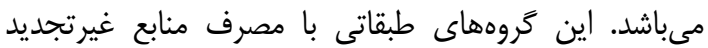

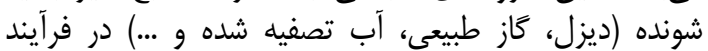

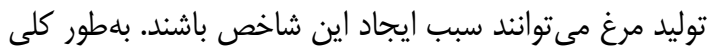

شكلهاى fأ و ه به ترتيب سهم نمادههاى ورودى به مزرعها

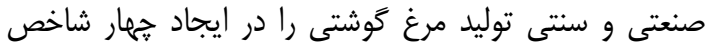

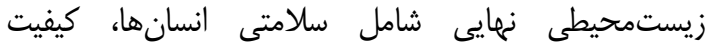

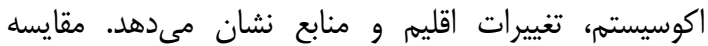

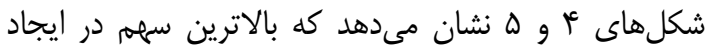

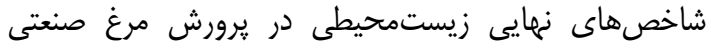

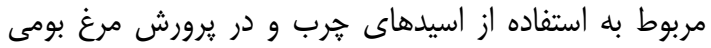

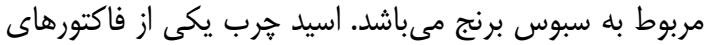

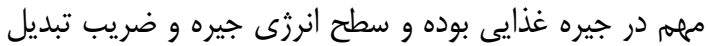
غذايى را افزايش و هزينههاى توليد مرغ توز

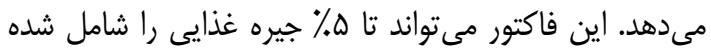

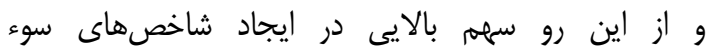

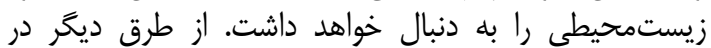

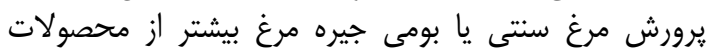

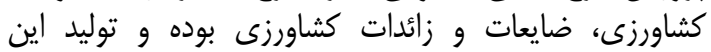

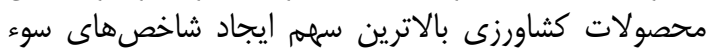

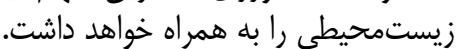

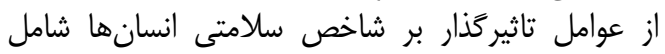

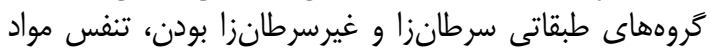

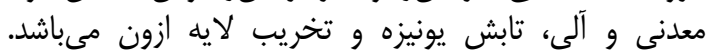

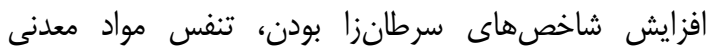

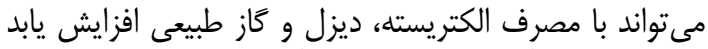

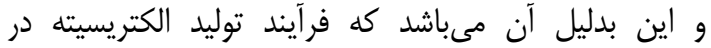

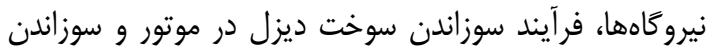

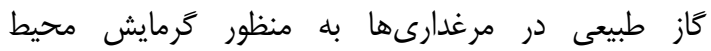

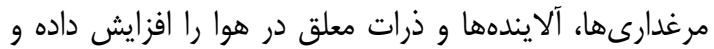

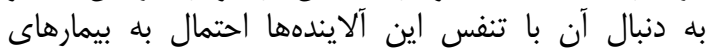

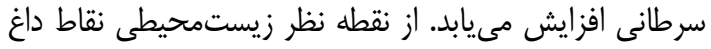

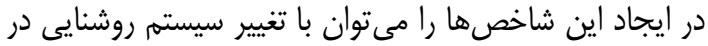

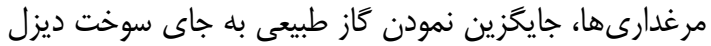

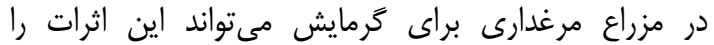

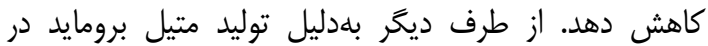

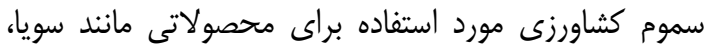

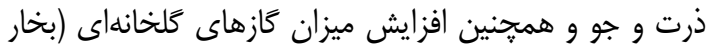

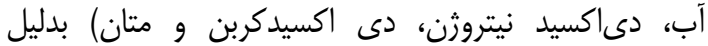

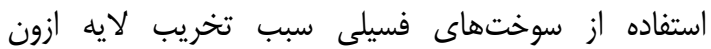
مى

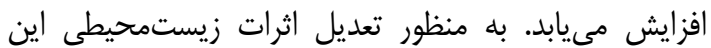

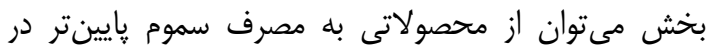

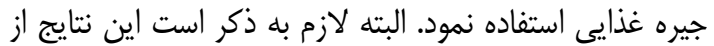

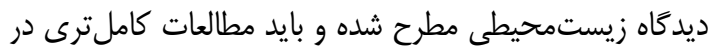

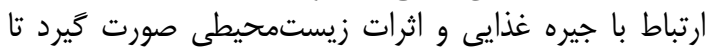

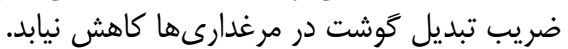

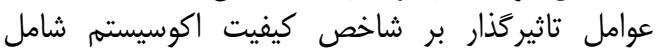

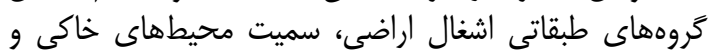

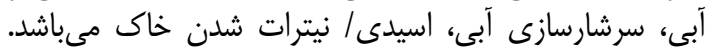

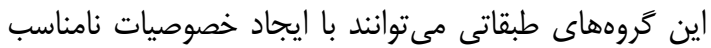

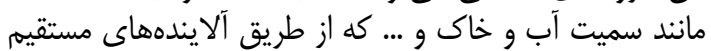

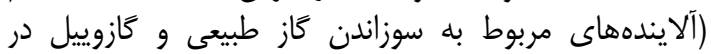


نتايج بررسى شاخصهاى نهايى توليد يك كيلوگرم مرغ كوشتى (9) در دو سيستم مختلف به روش

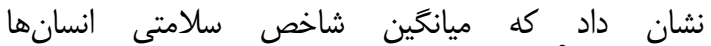
(PDF.m².yr) (DALY)

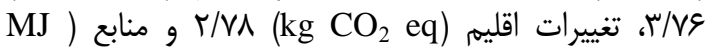

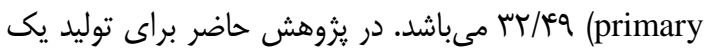

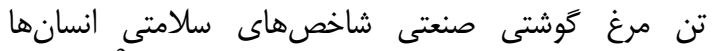
(PDF.m².yr) (DALY)

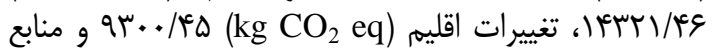

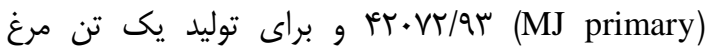
كوشتى به روش سنتى شاخصهاى سلامتى انسانها (PDF.m².yr) (DALY)

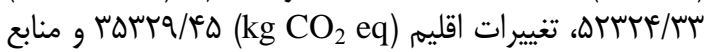

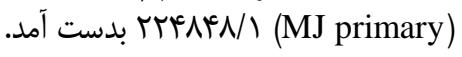

اين شاخص نشان مىدهد كه در آينده براى جايكزين يا توليد إنيد

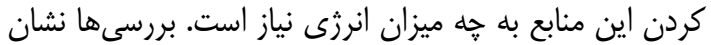

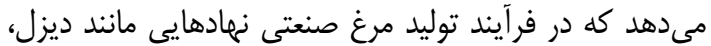

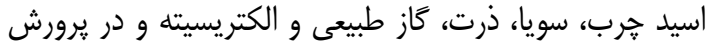

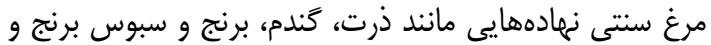

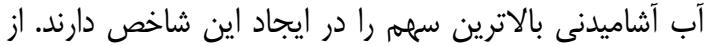

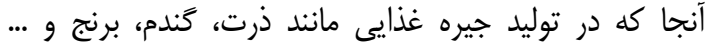

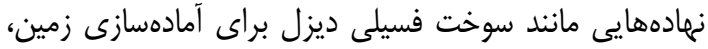

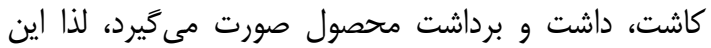

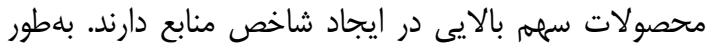

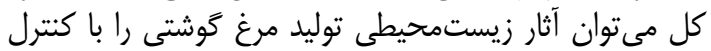

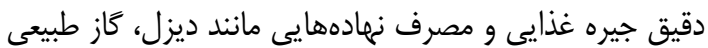
و الكتريسته در سالنهاى يرورش تا حدود زيادى كنترل نمودان.

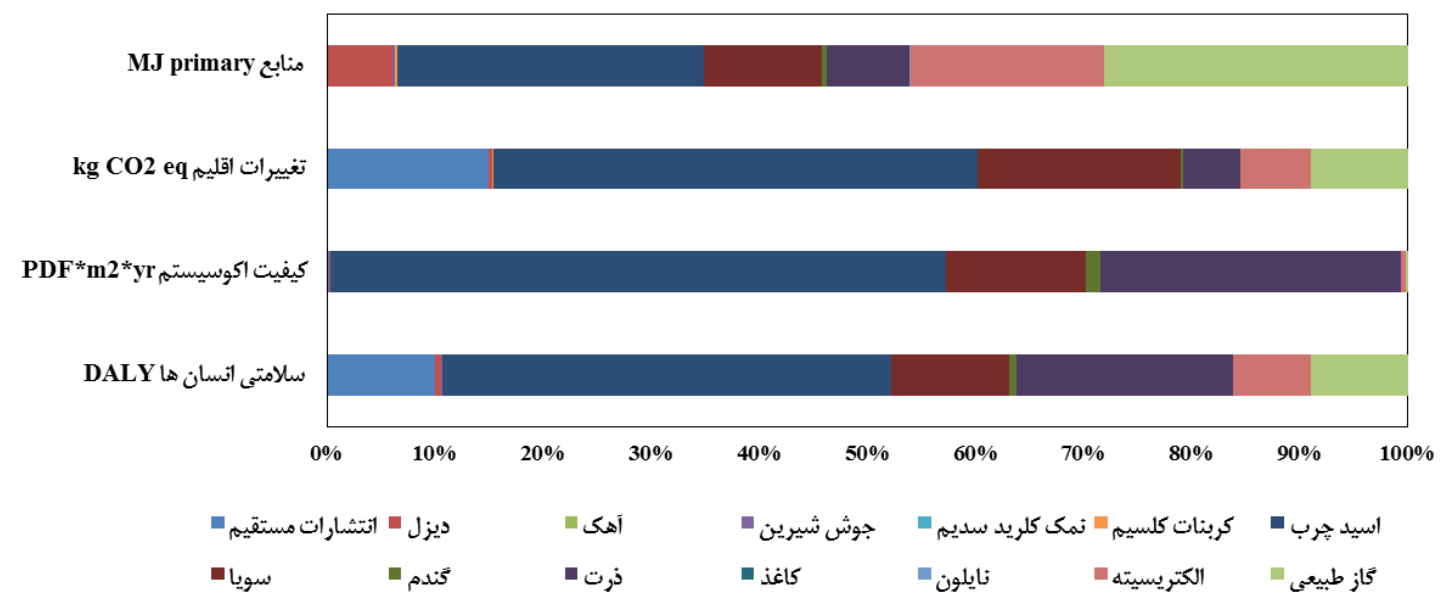

شكل ع- سهم هريك از نهادههاى ورودى در توليد مرغ گَوشتى به روش صنعتى بر شاخصهاى نهايى زيستمحيطى

Figure 4. Contribution of inputs to endpoint environmental indicators of the broiler chicken production in the industrial method

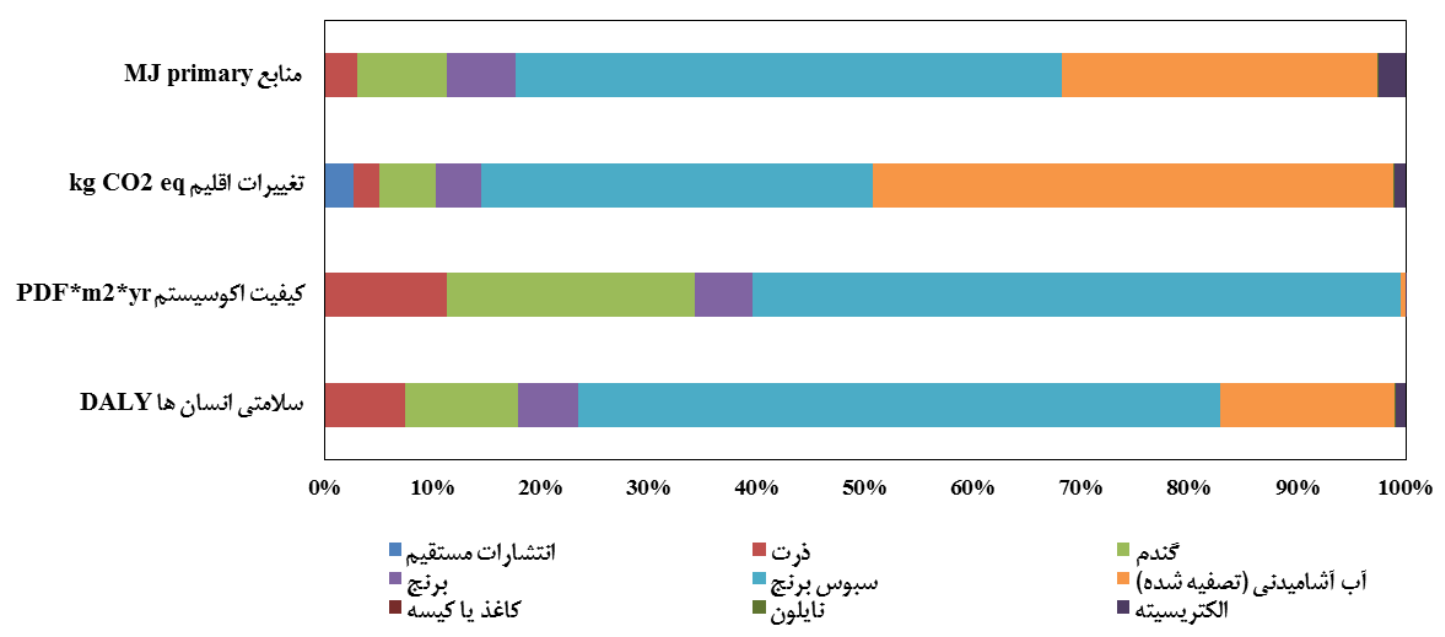

شكل ه- سهم هريك از نهادهاى ورودى در توليد مرغ گوشتى به روش سنتى بر شاخصهاى نهايى زيستمحيطى

Figure 5. Contribution of inputs to endpoint environmental indicators of the broiler chicken production in the traditional method 
دوره رشد در هر دو روش يرورش، رسيدن به وزن ميانخين دو

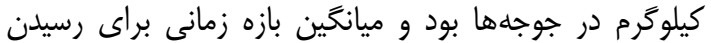

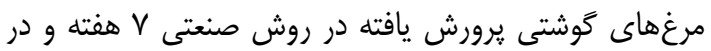

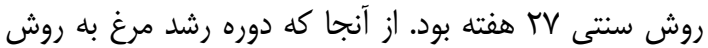

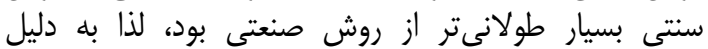

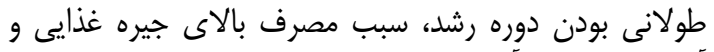

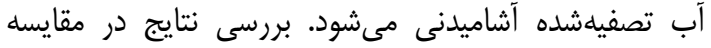

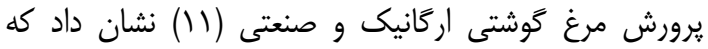

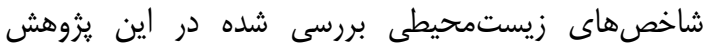

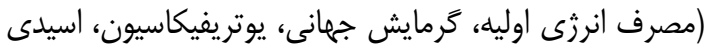

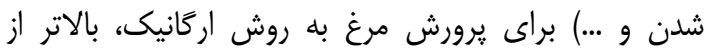
روش صنعتى بود كه با نتايج يثوهش حاضر برو همخوانى دارد.
بلمنظور مقايسه شاخصهاى نهايى زيستمحيطى با بإيد

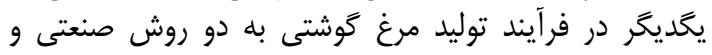

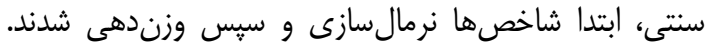

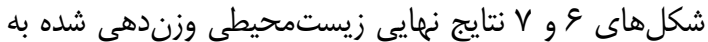

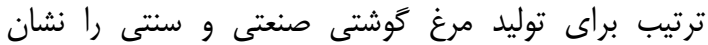

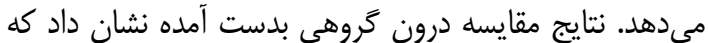

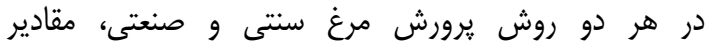
شاخصهاى سلامتى انسانها، كيفيت اكوسيستم و تغييرات

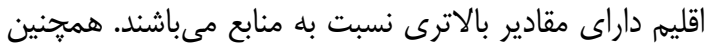

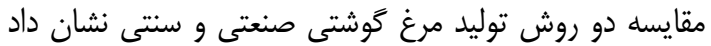

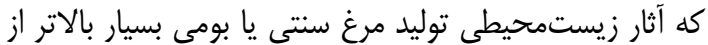

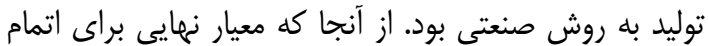

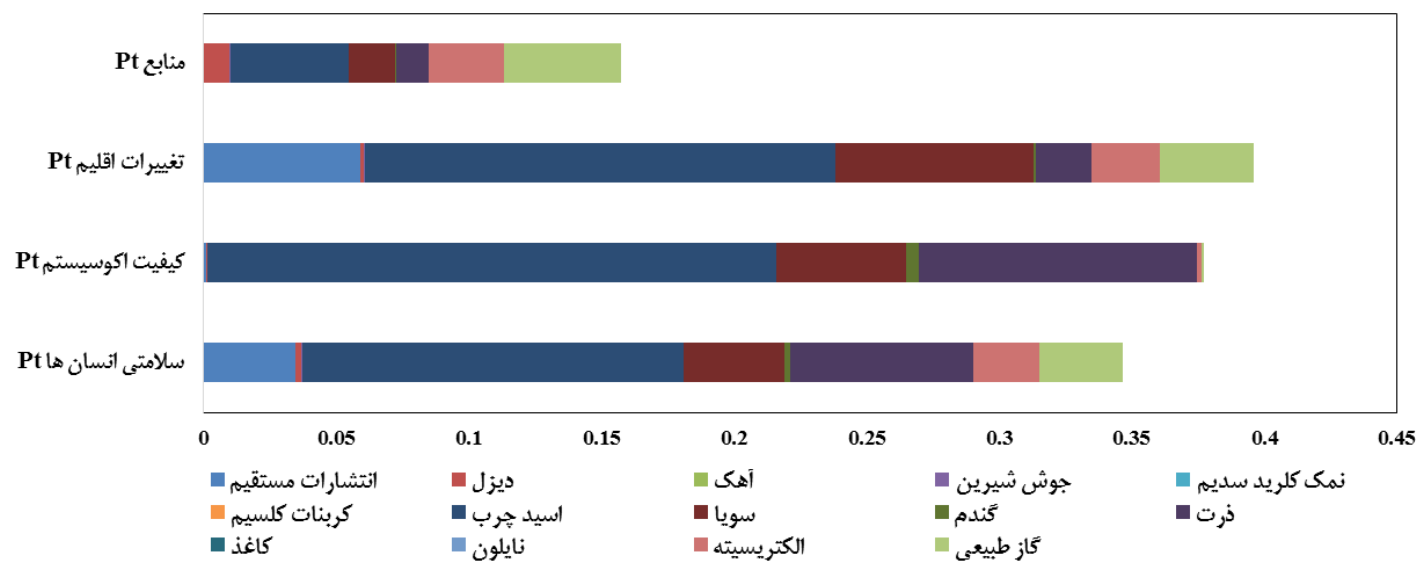

شكل צ- سهم هريك از نهادههاى ورودى در توليد مرغ گَشتى به روش صنعتى بر شاخصهاى نهايى وزندهى شده زيستمحيطى Figure 6. Contribution of inputs to broiler chicken production on weighted environmental indicators of the in the industrial method

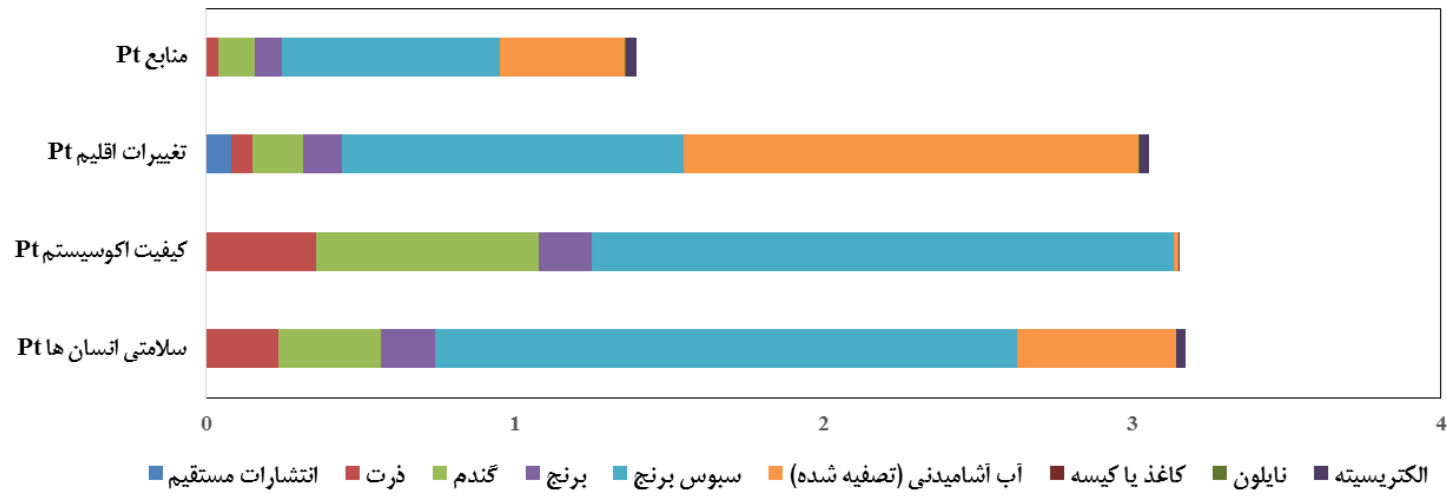

شكل V- سهم هريك از نهادههاى ورودى در توليد مرغ گَشتى به روش ستتى بر شاخصهاى نهايى وزندهى شده زيستمحيطى

Figure 7. Contribution of inputs to broiler chicken production on weighted environmental indicators of the in the traditional method 


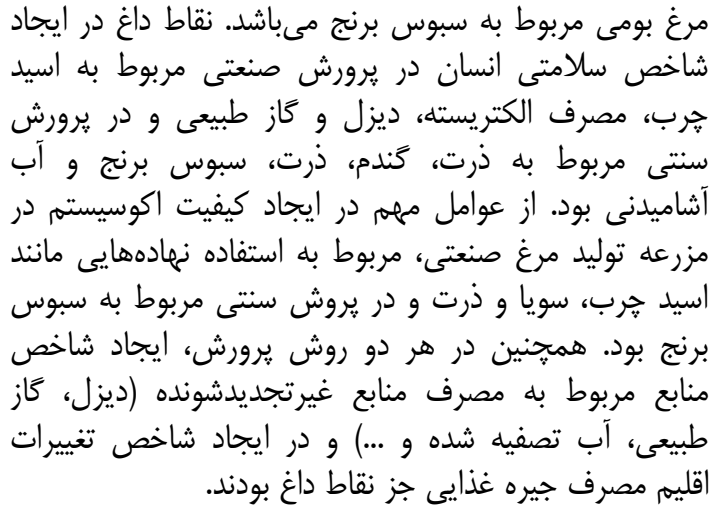

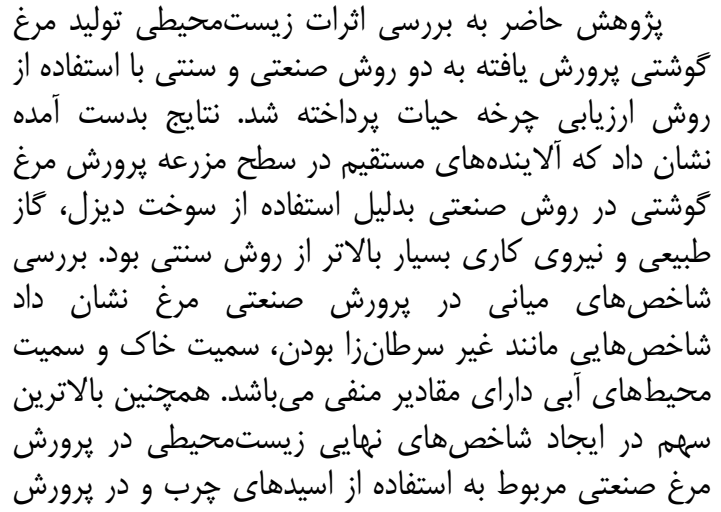

منابع

1. Aghamoradi, L. 2016. The effects of some environmental indicators of broiler chickens production cycle in Hamadan city using Life Cycle Assessment (LCA). M.Sc. Thesis, Bu-Ali Sina University, Hamedan, Iran.

2. Anonymous. 2016. Agricultural statistical. Iran Agricultural Ministry, Tehran, Iran.

3. Boer, D.I.J.M. 2002. Environmental impact assessment of conventional and organic milk production. Livestock Production Science, 80(1-2): 69-77.

4. Brentrup, F., J. Küsters, H. Kuhlmann and J. Lammel. 2004. Environmental impact assessment of agricultural production systems using the life cycle assessment (LCA) methodology. I. Theoretical concept of a LCA method tailored to crop production. European Journal of Agronomy, 20: 247-264.

5. Cerutti, A.K., S. Bruun, G.L. Beccaro and G. Bounous. 2011. A review of studies applying environmental impact assessment methods on fruit production systems. Journal of Environmental Management, 92: 2277-86.

6. Cesari, V., M. Zucali, A. Sandrucci, A. Tamburini, L. Bava and I. Toschi. 2017. Environmental impact assessment of an Italian vertically integrated broiler system through a Life Cycle approach. Journal of Cleaner Production, 143: 904-911.

7. Dones, R., C. Bauer, R. Bolliger, B. Burger, M. Faist Emmenegger, R. Frischknecht, T. Heck, N. Jungbluth, A. Röder and M. Tuchschmid. 2007. Life Cycle Inventories of Energy Systems: Results for current systems in Switzerland and Other UCTE Countries. Paul Scherrer Institut Villigen, Swiss Centre for Life Cycle Inventories, Dübendorf, Switzerland. Ecoinvent Report, No. 5.

8. González-García, S., Z. Gomez-Fernández, A. CláudiaDias, G. Feijoo, M.T. Moreira and L. Arroja. 2014. Life Cycle Assessment of broiler chicken production: a Portuguese case study. Journal of Cleaner Production, 74: 125-134.

9. Josue Lopez-Andres, J., A. Alfonso Aguilar-Lasserre, L. Fernando Morales-Mendoza, C. AzzaroPantel, J. Raúl Perez-Gallardo and J. Octavio Rico-Contreras. 2018. Environmental impact assessment of chicken meat production via an integrated methodology based on LCA, simulation and genetic algorithms. Journal of Cleaner Production, 174: 477-491.

10. Kalhor, T., A. Rajabipour, A. Akram and M. Sharifi. 2016. Environmental impact assessment of chicken meat production using life cycle assessment. Information processing in agriculture, 3: 262271.

11. Leinonen, I., A.G. Williams, J. Wiseman, J. Guy and I. Kyriazakis. 2011. Predicting the environmental impacts of chicken systems in the United Kingdom through a life cycle assessment: Broiler production systems. Poultry Science, 91(1): 8-25.

12. MacLeod, M., P. Gerber, A. Mottet, G. Tempio, A. Falcucci, C. Opio, T. Vellinga, B. Henderson and H. Steinfeld. 2013. Greenhouse gas emissions from pig and chicken supply chains-A global life cycle assessment. Food and Agriculture Organization of the United Nations (FAO), Rome, Italy.

13. Magdelaine, P., M.P. Spiess and E. Valceschini. 2008. Poultry meat consumption trends in Europe. World's Poultry Science Journal, 64: 53-64.

14. Nguyen, T.L.T. and J.E. Hermansen. 2012. System expansion for handling co-products in LCA of sugar cane bio-energy systems: GHG consequences of using molasses for ethanol production. Applied Energy, 89: 254-261.

15. Skunca, D., I. Tomasevic, I. Nastasijevic, V. Tomovic and I. Djekic. 2018. Life cycle assessment of the chicken meat chain. Journal of Cleaner Production, 184: 440-450.

16. West, T.O. and G. Marland. 2002. A synthesis of carbon sequestration, carbon emissions, and net carbon flux in agriculture: comparing tillage practices in the United States. Agriculture, Ecosystems and Environment, 91: 217-32.

17. Wiedemann, S.G., E.J. McGahan and C.M. Murphy. 2017. Resource use and environmental impacts from Australian chicken meat production. Journal of Cleaner Production, 140: 675-684. 


\title{
Evaluation of the Environmental Impact of Industrial and Traditional Broiler Chicken Production by Using Life Cycle Assessment
}

\author{
Behrooz Faramarzi $^{1}$, Ali Motevali ${ }^{2}$, Seyyed Jafar Hashemi ${ }^{3}$ and Ashkan Nabavi-Pelesaraei ${ }^{4}$
}

1- M.Sc. Student of Biosystem Engineering, Sari Agricultural Sciences and Natural Resources University, Sari, Iran

2- Assistant Professor of Biosystem Engineering, Sari Agricultural Sciences and Natural Resources University, Sari, Iran (Corresponding author: a.motevali@sanru.ac.ir)

3- Associate Professor of Biosystem Engineering, Sari Agricultural Sciences and Natural Resources University, Sari, Iran

4- PhD Graduated, Department of Agricultural Machinery Engineering, Faculty of Agricultural Engineering and Technology, College of Agriculture and Natural Resources, University of Tehran, Karaj, Iran Received: June 11, $2019 \quad$ Accepted: August 26, 2019

\begin{abstract}
Poultry meat with a high share in the food consumption is one of the most basic products for supplying protein to households. Due to the high amount of pollutants in this part, the environmental impact of the production of this product is necessary. In the present study, the environmental impact of broiler chicken production in both industrial and traditional breeding methods were evaluated using Life cycle assessment method in Mazandaran province. The environmental impacts of producing one ton of poultry were evaluated by IMPCAT 2002 methods in the form of 15 midpoint environmental indicators and 4 endpoint environmental indicators. The results of industrial chicken breeding showed that inputs such as fatty acids, food (soybean meal, corn, and wheat) and energy (electricity, diesel and natural gas) have the highest contribution to creating different midpoint environmental indicators. At the same time evaluating environmental indicators of chicken production in the traditional method showed that the highest share in the most environmental indicators related to the use of rice bran. Also the results showed that for the production of a one ton of industrial broiler chicken, the human health indicators 0.0063 (DALY), ecosystem quality 14321.46 (PDF.m $\left.{ }^{2} . y r\right)$, climate change $9300.45\left(\mathrm{~kg} \mathrm{CO}_{2} \mathrm{eq}\right.$ ), and resources 42072.93 (MJ primary) and for the production of one ton of broiler chicken in the traditional way (organic), human health indices 0.0262 (DALY), ecosystem quality 52324.33 (PDF.m ${ }^{2}$.yr), climate change $35329.45\left(\mathrm{~kg} \mathrm{CO}_{2}\right.$ eq) and resources 224848.1 (MJ primary). The overall results obtained from weighted environmental indicators showed that the production of broiler chickens by the industrial method due to the short growth period of the chicks, had lower environmental effects than traditional production methods.
\end{abstract}

Keywords: Environmental Impact, Broiler Chicken, IMPACT 2002, Life Cycle Assessment 